\title{
Assessment of metallic materials required for shock stress protection
}

\author{
Sorin V. Cristea, Marius Bibu, Cristian Deac*, Alina Gligor, and Marinela Inta \\ Lucian Blaga University of Sibiu, Romania, Department of Industrial Engineering and Management, Emil \\ Cioran Str., 1, Sibiu, Romania
}

\begin{abstract}
Establishing which metallic materials are suitable to be used for the protection of operators and machinery, when subjected to stress impact in the drilling industry, for surface exploitation, mines and quarries, is a complex process. Due to the harsh operating conditions, a careful evaluation of the various materials used is of utmost importance. This paper addresses the issues relating to the methodology of determining the appropriate homogenous materials to be used, based on a correspondence between their characteristics and applications. Starting with a list of specific operating conditions, one has established a set of requirements and has assessed the market; the recommended materials for the job are alloy steels and aluminum alloys.
\end{abstract}

\section{Introduction}

The process of refining the requirements provided by a recipient of a technical system represents a first step, followed by a good management of the project to implement the system can guarantee its success. When the project concerns the technical endowment or, more precisely, when purchasing a system is expensive, choosing the optimum technical solution in terms of the beneficiary ensures an optimum ratio between costs and performances, for a punctual, specific situation.

The paper is divided into three chapters. The introduction presents the current state of theoretical developments of the concepts that led to the establishment of a rapid and simple methodology for linking certain requirements to the materials' features.

In the second chapter the applied methodology is presented. Therefore, it is proposed to quantify certain requirements of current and future beneficiaries of equipment for surface quarrying mining. The requirements were limited to a subsystem of this type of equipment, namely the protection plates at shock and a correlation with market demand was established.

The third chapter presents the results obtained, in the end being presented the conclusions in the approach proposed.

Human activities are often conducted in areas at risk. Risks exist for both the technology as well as for its operator. For quarrying machinery for resource exploitation, a separate category of risks is represented by those generated by a possible environmental physical aggression. In other words, the machines are in a position to be impacted by elements of the field. This is due not so much to the movement of the machinery, performed most often at speeds below $20 \mathrm{~km} / \mathrm{h}$, but especially of rocks and earth movements under the influence of environmental factors often unpredictable.

*Corresponding author: cristian.deac@ulbsibiu.ro 
Stresses on impact are usually shock stresses. The choice of subsystems' materials for protection to these stresses, protection defined herein limiting, just as a set of technical solutions aimed at avoiding/limiting damage to technology and altering the health of the operator, requires a detailed risk analysis in relation to technical solutions available. The first step in developing means of protection and limiting the effects of shock stresses were made in the military. It has started with the leather shield, then wood, wood and metal, then homogeneous metal plates and non-homogeneous and layered structures followed.

In the field of quarrying machines the use of metal, homogeneous protective plates remains the basic constructive solution, primarily due to the low cost price. Increasing the performance of these protective plates involves the use of materials that can provide an optimal ratio between characteristics and costs.

In addressing the issue we began with the concepts of systems engineering and operational research. Systems engineering, widely represented in specialty papers, for example [1-7] is the set of integrated activities that controls a project as a whole, implements and integrates a comprehensive set of interacting components and systems in order to ensure satisfaction of all users and other stakeholders, within the restrictions due to dynamic operational environments in which the system works. From the operational research area [8-9] analysis and multi-criteria optimization elements were used.

\section{Methodology}

We have aimed to establish a practical and rapid methodology of choosing the necessary materials for a protection solution against shock stresses from the recipient's requirements and the destination of the machinery.

We started with a general description of the operational capabilities of the machinery in quarrying. The specific requirements for active subsystems were not evaluated: mills, hoes, blades, dippers, etc. We reviewed the threat to be countered and the threatening environment in which the machine must operate was evaluated. Two examples of some extreme situations are shown in Figure 1.

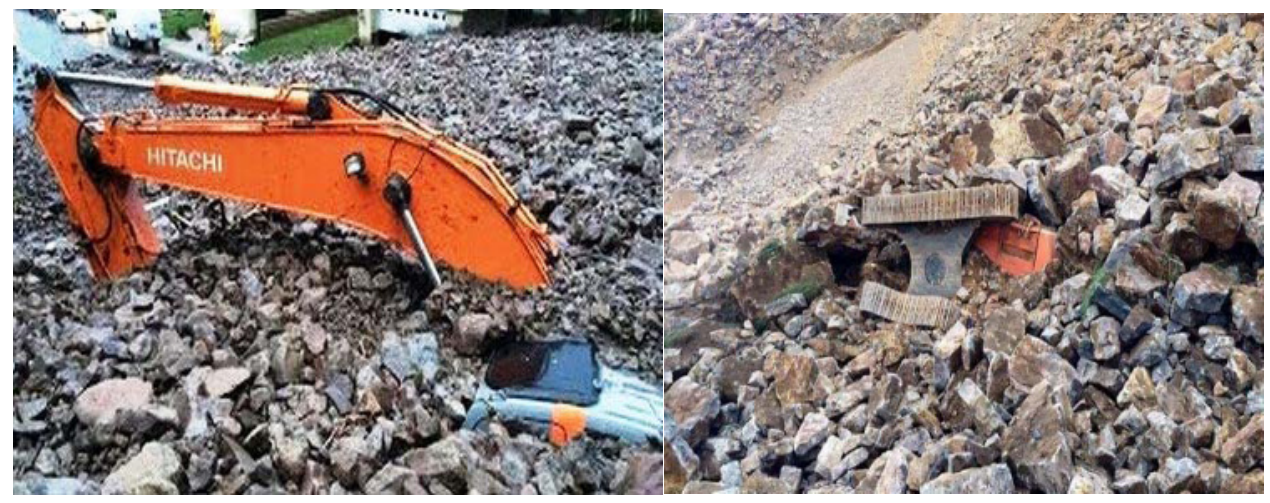

a) rock slides on the machinery.

b) landslides covering the machinery.

Fig. 1. Extreme environmental situations of aggression on quarrying machinery.

Existing solutions to provide protection to identify disadvantages were examined. It has been found that the basic solution is the protection with homogeneous metallic plates. It was not taken into account to ensure total protection against any aggression because such solution leads to a total mass of equipment that would significantly affect mobility and progression in the field. Only the aggression of rocks with variable hardness and geometry was considered, often with sharp edges and impact energies of up to $10 \mathrm{~kJ}$ (the equivalent of a mass of $200 \mathrm{~kg}$ falling from a $5 \mathrm{~m}$ height). 
Operational performance parameters of protective plates were identified.

For converting certain qualitative formulation into numbers, an index of the beneficiary's need $i_{n b}$ was established, by comparing the number of references of a characteristic to the total number of characteristics to be assessed. The weighted level of confidence of $i_{p i}$ requirement was calculated, depending on the degree of restriction (must be / is desirable) with the relationship:

$$
i_{p i}=1 /\left[\left(1-i_{n b}\right)(N-1)\right]
$$

Where $\mathrm{N}$ is the number of opinions expressed.

The calculation is an adaptation after [10-12] and the results are interpreted as an affinity diagram.

The characteristics of some groups of materials were reviewed. The needs of some beneficiaries were identified. The market demand for homogeneous metal plates was evaluated. The suggested materials for making protective plates with good resistance to shock stresses were settled. Their characteristics were quantified and the material proper to the defined punctual situation was determined.

\section{Results obtained}

There were identified eleven characteristics of protection plates to shock stresses. Ten beneficiaries or potential beneficiaries of these types of equipment were identified, who were asked to specify the features they consider most important. The index of the beneficiary's need for this and the requirement's weighted level of confidence are shown in Table 1.

Table 1. The beneficiary's need index and the weighted level of confidence of the characteristic.

\begin{tabular}{|c|l|c|c|c|l|c|c|}
\hline $\begin{array}{c}\text { Crt. } \\
\text { no. }\end{array}$ & \multicolumn{1}{|c|}{ Characteristic } & $\boldsymbol{i}_{\boldsymbol{n} \boldsymbol{b}}$ & $\boldsymbol{i}_{\boldsymbol{p} \boldsymbol{i}}$ & $\begin{array}{c}\text { Crt. } \\
\text { no. }\end{array}$ & \multicolumn{1}{|c|}{ Characteristic } & $\boldsymbol{i}_{\boldsymbol{n} \boldsymbol{b}}$ & $\boldsymbol{i}_{\boldsymbol{p} \boldsymbol{i}}$ \\
\hline 1 & Density & 0.36 & 0.16 & 7 & Abrasion resistance & 0.73 & 0.37 \\
\hline 2 & Hardness & 0.91 & 1.00 & 8 & Corrosion resistance & 0.55 & 0.22 \\
\hline 3 & Thermal expansion & 0.27 & 0.14 & 9 & Machinability & 0.09 & 0.11 \\
\hline 4 & Mechanical durability & 0.45 & 0.18 & 10 & $\begin{array}{l}\text { Easy } \\
\text { mounting/dismounting }\end{array}$ & 0.27 & 0.14 \\
\hline 5 & $\begin{array}{l}\text { Impact bending } \\
\text { strength }\end{array}$ & 0.64 & 0.28 & 11 & 0.18 & 0.12 \\
\hline 6 & Chemical resistance & 0.27 & 0.14 & \multicolumn{6}{|l}{} \\
\hline
\end{tabular}

It can be noticed that machinability issues are not particularly significant to the beneficiary. Moreover, the problem of hardness is significantly less important than the ease of mountingdismounting operations. Last but not least, it can be noticed that hardness and abrasion resistance are absolutely needed characteristics, hardness being mentioned by all respondents.

Evaluation of results, given the large size of the protective plates in general and cost prices the field of materials related to ferrous and non-ferrous alloys was limited.

The market demand was analyzed. Medium hardness materials were considered, because they enable a better hardness/impact resistance ratio than materials with high or low hardness. Weldability and good machinability on high temperatures considerations have limited the scope to weak or alloyed temperable steels or aluminum alloys.

As the number of producers of homogeneous metal plates is large, the portfolio of customers was considered as an adequate selection criterion.

For the materials for which data was found, their composition was also considered, necessary to further, detailed studies.

In terms of Romanian steel, OB steels were identified, alloy steels with special destination. Their characteristics are shown in Table 2 and the compositions in Table 3. 
From manufacturers of homogeneous metal plates for impact protection there were chosen: Swedish Oxelosund Steel AB - Sweden for laminate plates of alloy steel - Hardox and Kaiser Aluminium Corporation for aluminum alloy plates. There were also considered Aluminium Company of America - ALCOA, USA, ALCAN - England and Pekingese - France.

Table 2. Characteristics of alloy OB 2 - OB 6 ([13]).

\begin{tabular}{|c|c|c|c|c|c|c|c|}
\hline \multirow{2}{*}{ Alloy } & $\mathbf{R}_{\mathrm{p} \mathrm{0,2}}$ & $\mathbf{R}_{\mathbf{m}}$ & $\mathbf{A}$ & $\mathbf{Z}$ & \multirow{2}{*}{$\frac{\mathrm{KCU}}{\left[\mathrm{daJ} / \mathrm{cm}^{2}\right]}$} & \multirow{2}{*}{ HB } & \multirow{2}{*}{ HRC } \\
\hline & \multicolumn{2}{|c|}{$\left[\mathrm{daN} / \mathbf{m m}^{2}\right]$} & \multicolumn{2}{|c|}{$[\%]$} & & & \\
\hline OB 2 & 100 & 110 & 15 & 55 & $6-12$ & $285-341$ & $28.3-35.0$ \\
\hline OB 3 & $70-110$ & $105-120$ & $10-15$ & $30-50$ & $9-11$ & $285-341$ & $28.3-35.0$ \\
\hline OB 4 & $90-110$ & $100-120$ & $12-15$ & $45-55$ & $7-11$ & $285-341$ & $28.3-35.0$ \\
\hline OB 5 & $90-110$ & $105-115$ & $12-15$ & $24-25$ & $10-14$ & $285-341$ & $28.3-35.0$ \\
\hline OB 6 & $74-78$ & $91-94$ & 17.5 & $34-39$ & $5-6$ & $262-311$ & $24.8-31.5$ \\
\hline
\end{tabular}

Table 3. Characteristics of alloy OB 2 - OB 6 ([13]).

\begin{tabular}{|c|c|c|c|c|c|c|c|c|}
\hline \multirow{2}{*}{ Alloy } & \multicolumn{7}{|c|}{ Chemical composition [ \% ] } \\
\cline { 2 - 9 } & $\mathbf{C}$ & $\mathbf{S i}$ & $\mathbf{M n}$ & $\mathbf{C r}$ & $\mathbf{M o}$ & $\mathbf{N i}$ & P & S \\
\hline OB 2 & $0.25-0.31$ & $0.18-0.35$ & $0.30-0.55$ & $1.80-2.3$ & $0.25-0.35$ & Max.0.5 & 0.030 & 0.030 \\
\hline OB 3 & $0.28-0.34$ & $0.18-0.35$ & $0.30-0.55$ & $1.40-1.9$ & $0.25-0.35$ & $1.00-1.5$ & 0.030 & 0.030 \\
\hline OB 4 & $0.28-0.34$ & $0.18-0.35$ & $0.30-0.50$ & $1.80-2.3$ & $0.28-0.38$ & $1.50-1.9$ & 0.030 & 0.030 \\
\hline OB 5 & $0.27-0.33$ & $0.18-0.35$ & $0.30-0.50$ & $1.80-2.3$ & $0.28-0.38$ & $1.80-2.3$ & 0.030 & 0.030 \\
\hline OB 6 & $0.24-0.31$ & $0.20-0.40$ & $0.30-0.60$ & $1.20-1.75$ & $0.25-0.35$ & $3.00-3.5$ & 0.025 & 0.025 \\
\hline
\end{tabular}

Hardness and tensile strength for several Hardox steels are shown in Table 4, and their composition in Table 5.

Table 4. Hardness and tensile strength of Hardox alloys ([14]).

\begin{tabular}{|c|c|c|}
\hline Alloy & Hardness HBW & $\boldsymbol{\sigma}_{\mathbf{r}}[\mathbf{M P a}]$ \\
\hline 400 & $370 \ldots 430$ & $900 \ldots 1100$ \\
\hline 450 & $390 \ldots 475$ & $1000 \ldots 1300$ \\
\hline $450 \mathrm{CR}^{*}$ & $425 \ldots 475$ & $1400 \ldots 1600$ \\
\hline 500 & $450 \ldots 540$ & $1250 \ldots 1400$ \\
\hline 550 & $525 \ldots 575$ & - \\
\hline HITUF & $310 \ldots 370$ & 850 \\
\hline Extreme & $57 \ldots 63 \mathrm{HRC}$ & - \\
\hline
\end{tabular}

* With good resistance to abrasion.

Of the Kaiser Aluminium Corporation 7000 series aluminum alloys, alloys of Al-Zn-Mg type were identified. The chemical composition of two alloys is shown in Table 6 .

Reviewing the properties of various aluminum alloys it has been observed that they have hardness between $40 \mathrm{HB}$ and $70 \mathrm{HB}$. For a proper shock stress protection, we believe that the required hardness should be of at least $70 \mathrm{HB}$.

Table 5. Chemical composition of certain Hardox alloys ([14]).

\begin{tabular}{|c|c|c|c|c|c|c|c|c|c|}
\hline \multirow{2}{*}{ Alloy } & \multicolumn{9}{|c|}{ Chemical composition [ \% ] } \\
\cline { 2 - 11 } & C & Si & Mn & Cr & Ni & Mo & B & P & S \\
\hline 400 & 0.32 & 0.7 & 1.6 & 1.4 & 1.5 & 0.6 & 0.004 & 0.025 & 0.01 \\
\hline 450 & 0.26 & 0.7 & 1.6 & 1.4 & 1.5 & 0.6 & 0.005 & 0.025 & 0.01 \\
\hline $450 \mathrm{CR}^{*}$ & 0.18 & 0.25 & 1.3 & 0.1 & 0.1 & 0.04 & 0.003 & 0.015 & 0.004 \\
\hline 500 & 0.3 & 0.7 & 1.6 & 1.5 & 1.5 & 0.6 & 0.005 & 0.02 & 0.01 \\
\hline 550 & 0.37 & 0.5 & 1.3 & 1.4 & 1.4 & 0.6 & 0.004 & 0.020 & 0.01 \\
\hline HITUF & 0.2 & 0.6 & 1.6 & 0.7 & 2.0 & 0.7 & 0.005 & 0.05 & 0.02 \\
\hline Extremes & 0.47 & 0.5 & 1.4 & 1.2 & 2.5 & 0.8 & 0.005 & 0.015 & 0.01 \\
\hline
\end{tabular}


Table 6.Chemical composition of some Al-Zn-Mg alloys ([15]).

\begin{tabular}{|c|c|c|c|c|c|c|c|c|}
\hline \multirow{2}{*}{ Alloy } & \multicolumn{9}{|c|}{ Chemical composition [ \% ] } \\
\cline { 2 - 9 } & Al & Si & Fe & Zn & Mn & Mg & Bi & Cr \\
\hline $\mathrm{Cu} \mathrm{Ni7439,7440}$ & Min 80 & $0.1-10$ & $0.1-1.0$ & 0.1 & 5.0 & $0.1-5.0$ & $0.1-3.0$ & $0.1-1.0$ \\
\hline $\mathrm{Cu} \mathrm{Cr7439,7440}$ & Min 80 & $0.1-15$ & $0.1-5.0$ & $0.1-10$ & $0.1-5.0$ & $0.1--5.0$ & $0.1-3.0$ & $0.1-5.0$ \\
\hline
\end{tabular}

The material's properties were evaluated in the order of the characteristic's weighted value of confidence $i_{p i}$ (Table 1). Scores between 0.0 and 1.0 were given for the assessed characteristic's values, with 0.0 for the minimum value to 1.0 for the maximum amount for those materials. The first five features were analyzed, in decreasing order of the beneficiary's need $i_{n b}$, where data was willing. There were established the recommended materials for making protection plates with shock applications.

\section{Conclusions}

The beneficiary's need index is easier to interpret in terms of quality than the need's weighted level of confidence.

To achieve impact protection plates weldable steels are recommended, usuallylow alloyed and, in some cases, medium alloyed. The chemical composition of these steels is generally as follows: $0.23 \ldots 0.34 \% \mathrm{C} ; 0.18 \ldots 1.60 \% \mathrm{Si} ; 0.30 \ldots 1.60 \% \mathrm{Mn} ; 0.30 \ldots 2.30 \% \mathrm{Cr} ; 0.15 \ldots 0.38 \%$ Mo; 0.1 ... 3.50\% Ni. Most shock-resistant weldable steels that are commonly employed are processed as profiles, usually plates with thicknesses from 8-160 mm. By applying this methodology OB2 steel was determined of the domestic production and Hardox 450CR steel from Swedish Oxelosund Steel AB.

If after the evaluation of the general organizing solution of the machine, a significant reduction of its total mass is chosen, even with additional costs, aluminum alloys from the 7000 series are recommended. By applying this methodology, the 7710 alloy was selected, having a hardness of $120 \mathrm{HB}$.

Selecting a material to meet a well-defined need is effectively achieved in design, every day by engineers, metallurgists, materials science and engineering specialists or designers. Choosing a material at the stage of establishing a generic system solution suitable to a beneficiary, according to a set of characteristics, other than those analyzed in the design stage, has the advantage of better cost control.

In the speciality literature [16-18] most frequent approaches refer to specific behaviors occurring in the material or class of material for a set of given stresses, the paper proposes a rapid and easy methodology for the appropriate selection both of real stresses and the needs of a beneficiary. Of course, further analysis of its behavior in operation cannot be excluded.

\section{References}

1. $\quad * * *$, Systems Engineering Handbook, NASA Headquarters, ISBN 978-0-16-079747-7, 2007

2. $\quad * * *$, Systems Engineering Fundamentals, D.A.U./D.S.M.C Press, Virginia, USA, 22060$5565(2001)$

3. ***, Guide to the Systems Engineering Body of Knowledge (SEBoK), (Stevens Institute of Technology, 2014)

4. A. Kossiakoff A., W.N. Sweet, S.J. Seymour, S.M. Biemer, Systems Engineering Principles and Practice, 2nd ed. (Wiley, 2011)

5. Y. Bar-Yam, When Systems Engineering Fails --- Toward Complex Systems Engineering (IEEE International Conference on Systems, Man and Cybernetics, Washington DC, 2003)

6. S.N. Syed Salim, M. Zainon, Control Systems Engineering (Durian Tunggal Melaka, 2010) 
7. T.I. Ören, L. Yilmaz, Synergy of Systems Engineering and Modeling and Simulation (Proceedings of the SCS International Conference on Modeling and Simulation-Methodology, Tools, Software Applications, 2006)

8. H.A. Taha, Operations Research (Pearson/Prentice Hall, 2007)

9. J.B. Goldberg, Operations Research, Applications and Algorithms, 4th ed. (Thomson, 2004)

10. *** Materials Selection and Design, ASM Handbook, 20 (ASM International, 1997)

11. J.M. Regan, F.M. Downey, The TASCFORM Metodology: A tehnique for assessing comparative force modernization, $5^{\text {th }}$ ed. (TASC, 1993)

12. *** Properties and Selection: Irons, Steels, and High-Performance Alloys, ASM Handbook, $1,10^{\text {th }}$ ed. (ASM International, 1993)

13. S. Cristea, Blindaje omogene (Editura Academiei Fortelor Terestre, Sibiu, 2010)

14. *** High-strength steel - sheet, plate, coil, tube, profile (Swedish Steel Oxelosund AB, 2016)

15. *** Kaiser Aluminum (Kaiser Aluminum, 2016)

16. L.C. Jones, R.J. Llewellyn, Sliding abrasion resistance assessment of metallic materials for elevated temperature mineral processing conditions, Wear, 267, 11 (2009)

17. W. Hoffelner, Damage assessment in structural metallic materials for advanced nuclear plants, Journal of Materials Science, 45 (2010)

18. H. Zhu, T. Wei, D. Carr, R. Harrison, L. Edwards, W. Hoffelner, D. Seo, K. Maruyama, Assessment of Titanium Aluminide Alloys for High-Temperature NuclearStructural Applications, JOM, 64 (2012) 